\title{
Avaliações e percepções sociolinguísticas
}

DOI: http://dx.doi.org/10.21165/el.v50i1.3100

\section{Livia Oushiro'}

\section{Resumo}

Este artigo discute a importância dos estudos sobre avaliações e percepções sociolinguísticas, relativamente menos produtivos do que estudos sobre produção linguística, e apresenta alguns métodos e cuidados necessários para o desenvolvimento desse campo. Argumenta-se que, não obstante o consenso entre linguistas de que as formas linguísticas não se diferenciam em termos de correção, beleza ou agradabilidade, diferentes variantes adquirem, no uso linguístico, múltiplos significados, que fazem parte da competência comunicativa (HYMES, 1991 [1979]) dos membros da comunidade daí a ineficácia do discurso de combate ao preconceito linguístico pautado meramente na reiteração da diversidade linguística. O combate ao preconceito linguístico deve incorporar os resultados dos estudos sobre avaliações e percepções que se debruçam sobre os mecanismos de associação entre determinadas variantes e certos significados sociais.

Palavras-chave: avaliações; percepções; significados sociais; preconceito linguístico.

1 Universidade Estadual de Campinas (UNICAMP), Campinas, São Paulo, Brasil; oushiro@iel.unicamp.br; https://orcid.org/0000-0002-2165-3305 


\title{
Sociolinguistic evaluation and perceptions
}

\begin{abstract}
This article discusses the importance of studies on linguistic evaluation and perceptions, which have been relatively less productive than works on language production, and presents methods and necessary precautions for the development of the field. I argue that, although there is a consensus among linguists that linguistic variants do not differ in terms of correction, beauty, or pleasantness, different variants do acquire multiple meanings in language use, and the knowledge of these meanings is part of speakers' communicative competence (HYMES, 1991 [1979]) - hence the inefficacy of the discourse against language prejudice which is based purely on the argument of language diversity. The discourse against linguistic prejudice must incorporate the results from studies on language evaluation and perception regarding the mechanisms of association between certain variants and social meanings.
\end{abstract}

Keywords: evaluation; perceptions; social meanings; linguistic prejudice.

\section{Introdução}

Nos estudos linguísticos, é consenso que não existem formas "corretas" ou "incorretas", "mais bonitas" ou "mais feias", "agradáveis" ou "desagradáveis". No entanto, tal não é o senso comum: de modo geral, é comum ouvir avaliações e comentários a respeito de certos usos linguísticos, por exemplo, o uso de concordância nominal ou verbal não padrão (como "os menino gosta") como algo a ser higienizado da fala e da escrita das pessoas, missão atribuída principalmente aos professores de português. Por um lado, isso levanta a questão de por que os linguistas têm tido tanta dificuldade em divulgar suas descobertas e premissas científicas, direção na qual talvez estejamos dando nossos primeiros passos por meio da criação de blogs, revistas, podcasts e canais de divulgação científica². Por outro lado, contudo, é necessário reconhecer que os próprios linguistas pouco sabem a respeito dos mecanismos que levam à associação de certas formas linguísticas com determinados significados sociais - que vão muito além de noções de correção ou prestígio (ECKERT, 2008). Os significados sociais dos usos linguísticos podem abarcar desde identidades geográficas (como ser paulista, nordestino, gringo etc.) ou de grupos sociais (gays, jogadores de futebol, nerds, patricinhas etc.) até a atribuição de características pessoais aos falantes (ser pedante, culto, honesto, sofisticado etc.). Tais significados são sempre múltiplos e concomitantes.

2 A exemplo do blog \#Linguística (disponível em: https://www.blogs.unicamp.br/linguistica/); da Revista Roseta (disponível em: http://www.roseta.org.br); e do podcast Babel (disponível em: https://anchor.fm/babel-podcast), para citar apenas alguns. Acesso em: 15 jan. 2020. 
Conforme argumenta Guy (s/d), ao ouvir a voz de alguém no corredor ou no transporte público, facilmente é possível inferir seu sexo, sua faixa etária, sua origem geográfica, seu estado de saúde. A depender dos traços linguísticos ouvidos, associados ou não a outras pistas semióticas como o modo de se vestir e de se comportar, chega-se a inferências sobre a classe social, a etnia ou a orientação sexual do falante. Independentemente de se tais inferências são corretas ou não, os falantes de uma língua e membros de uma comunidade as realizam de modo quase automático em seu cotidiano. Purnell, Idsardi e Baugh (1999), em seu estudo sobre a discriminação habitacional diante de vozes associadas às variedades padrão, chicana e afroamericana do inglês norte-americano, com base na técnica de estímulos pareados (ver seção Métodos e conceitos centrais), demonstram que falantes de variedades não padrão do inglês têm menor probabilidade de conseguir alugar ou comprar uma residência em bairros cuja maioria populacional é branca, comparativamente a falantes da variedade padrão. Oushiro $(2015,2019)$ comenta que, em seu estudo de percepções sobre as variantes tepe e retroflexa de / $\mathrm{r}$ / em coda silábica entre ouvintes moradores da cidade de São Paulo, os participantes não tiveram dificuldade em atribuir características aos falantes e preencher um questionário de percepções com base em trechos curtos de 15 a 20 segundos de fala. Esses dois estudos exemplificam o quão automatizado é o hábito de fazer inferências sobre um indivíduo com base apenas em sua voz.

É possível entrever que o preconceito linguístico tem base em preconceitos sociais, de modo que usos linguísticos comuns na norma culta, mesmo que eventualmente proscritos na norma padrão - como dizer "me passa o sal", com pronome oblíquo no início da sentença, ou a elevação da vogal média postônica em "leite" [lej.ţi] -, não costumam ser alvo de correção ou estigma, ao passo que as concordâncias nominal e verbal, ou o rotacismo (como dizer "bicicreta") o são. Não é difícil perceber que muitos dos preconceitos relacionados aos usos linguísticos podem ser diretamente relacionados ao preconceito social quanto aos grupos que mais frequentemente fazem uso desses traços.

Assim, uma primeira pista sobre como os ouvintes chegam a inferências acerca de um falante pode vir de estudos sobre produção linguística. Dezenas de pesquisas têm demonstrado a correlação sistemática entre a concordância nominal ou a concordância verbal e o grau de escolaridade dos falantes (MENDES; OUSHIRO, 2015a; RUBIO; GONÇALVES, 2012), de modo que é possível concluir que o estigma quanto às formas não padrão dessas variáveis advém do fato de que tendem a ser empregadas por falantes menos escolarizados. Mendes e Oushiro (2015b), entretanto, em estudo comparativo sobre as percepções acerca da realização de /r/ em coda e da concordância nominal em São Paulo, mostram que, embora as correlações sociais observadas em trabalhos de produção linguística sobre essas duas variáveis sejam muito semelhantes (retroflexo e concordância não padrão favorecidas por homens, pessoas menos escolarizadas e de classe mais baixa), os significados sociais a elas atribuídos em experimentos de percepção não são os mesmos e não se hierarquizam do mesmo modo: enquanto os 
ouvintes associam a concordância não padrão a pessoas menos escolarizadas, de classe mais baixa, menos inteligentes e menos efeminadas, a realização retroflexa de $/ r /$ é associada principalmente a falantes do interior do estado, a residentes da região periférica da capital e a classes mais baixas. Desse modo, resultados de produção não podem ser interpretados diretamente como índices de identidades sociais.

A área da Sociolinguística tem se dedicado, nas últimas cinco décadas, a um estudo sistemático dos padrões de variação de diferentes comunidades e de variáveis as mais diversas, com base em amostras de fala de pessoas com diferentes perfis sociais ou seja, à descrição e à análise de como as pessoas falam -, mas pode-se afirmar que comparativamente há um número bem menor de estudos sobre a percepção e a avaliação dessas mesmas variáveis, ou seja, sobre o que os falantes pensam sobre esses traços, como eles pensam que falam (que pode não coincidir com seus usos efetivos) e que tipos de inferências fazem sobre outros indivíduos ao ouvi-los (OUSHIRO, 2016; FREITAG et al., 2016).

Este artigo tem o objetivo de discutir a importância de estudos sobre avaliações e percepções sociolinguísticas, assim como o de apresentar alguns dos métodos e dos cuidados necessários para o desenvolvimento de pesquisas sob esse tópico, o que se realiza nas duas seções subsequentes.

\section{Por que estudar avaliações e percepções}

No artigo seminal de Weinreich, Labov e Herzog (2006 [1968]), a questão da avaliação já figurava entre as cinco questões a que a Teoria da Variação e da Mudança deve responder (junto às questões do encaixamento, dos fatores condicionantes, da transição e da implementação). Sobre a questão da avaliação, os autores afirmam:

[...] o estudo do problema da avaliação na mudança linguística é um aspecto essencial da pesquisa que conduz a uma explicação da mudança. Não é difícil ver como traços de personalidade inconscientemente atribuídos a falantes de um dado subsistema determinariam a significação social da alternância para esse subsistema e assim seu desenvolvimento ou obsolescência como um todo. Mas o efeito dos valores sociais sobre o desenvolvimento interno de um sistema linguístico é uma questão mais difícil [...] (WEINREICH; LABOV; HERZOG, 2006 [1968], p. 103).

Nessa obra, o estudo da avaliação de formas linguísticas está diretamente relacionado com o interesse sobre a compreensão de como se dá a mudança linguística. A centralidade do conceito de avaliação também pode ser vista na definição laboviana da comunidade de fala, que, segundo o autor, 
[...] não é definida por nenhuma concordância marcada no uso de elementos linguísticos, mas sim pela participação num conjunto de normas compartilhadas; essas normas podem ser observadas em tipos de comportamento avaliativo explícito e pela uniformidade de padrões abstratos de variação que são invariantes no tocante a níveis particulares de uso. (LABOV, 2008 [1972], p. 150, grifo nosso).

São dois os critérios para definir um conjunto de falantes como pertencentes a uma mesma comunidade de fala, sendo um deles a avaliação explícita sobre as variantes e o segundo a aderência aos mesmos padrões de variação. Nesse sentido, nota-se a importância do estudo de avaliação linguística na definição de conceitos centrais para a teoria. Contudo, Weinreich, Labov e Herzog (2006 [1968]) já haviam entrevisto a dificuldade em analisar o efeito que valores sociais atribuídos a variantes linguísticas podem ter sobre o sistema, motivo pelo qual, talvez, a questão tenha sido relativamente preterida no desenvolvimento do campo de estudos. Na segunda edição de The Social Stratification of English in New York City, comentada pelo autor, Labov afirma que a terceira parte de sua tese, que trata da "avaliação social", forma uma parte essencial da metodologia; entretanto,

[a]s abordagens experimentais não se estabeleceram em sociolinguística de modo algum comparável aos estudos de produção da fala, que formam a base da Parte II. Embora cada um desses métodos experimentais tenha tido uma história de replicações e desenvolvimento, os estudos que incorporam experimentos são poucos quando comparados àqueles que não incorporam. (LABOV, 2006 [1966], p. 265, apud MENDES 2016, p. 426)3.

Desse modo, Labov avalia, em retrospectiva, que o emprego de métodos experimentais havia se desenvolvido relativamente menos do que as técnicas para estudos de produção. O estudo de avaliações e percepções tem se desenvolvido mais recentemente, em grande parte, pelo impulso das pesquisas que se encaixam na chamada "terceira onda" dos estudos sociolinguísticos (ECKERT, 2012), que se volta à análise de identidades, estilo e personae. Embora a tese de Labov, considerada por Eckert (2012) como emblemática de estudos da chamada "primeira onda", mostre claramente que o estudo de avaliações e de percepções não seja exclusivo da chamada "onda estilística", é indubitável que o interesse pela investigação dos significados sociais da variação e pelos modos pelos quais os falantes lançam mão desses significados na construção e na projeção de identidades por meio de usos linguísticos tem promovido o desenvolvimento de pesquisas que tratam mais propriamente das avaliações e das percepções sobre as formas linguísticas. Vale notar que, na chamada "terceira onda", o interesse sobre a mudança linguística tem ficado em segundo plano, em favor do tratamento dos significados sociais da variação

3 No original: "The experimental approaches did not take hold in sociolinguistics in any way comparable to the studies of speech production that formed the basis of Part II. Though each of these experimental methods has had a history of replications and development, the studies that incorporate experiments are few by comparison with those that do not.". 
que, segundo Eckert (2012), tendem a ser entendidos, nas duas primeiras ondas, como reflexo, mas não como construtores de categorias sociais.

Para além de questões dentro da própria teoria sociolinguística, os estudos sobre avaliações e percepções podem contribuir para a compreensão dos mecanismos que levam ao preconceito linguístico, ao explicitar quais significados sociais são atribuídos a quais variantes e variáveis, e, consequentemente, para melhores estratégias para seu combate; pode contribuir, também, com um ensino de outras línguas que contemple verdadeiramente a diversidade linguística.

O discurso de combate ao preconceito linguístico tem se pautado principalmente pela valorização da diversidade e pelo reconhecimento da variação como propriedade de toda e qualquer língua natural. Sabe-se, no entanto, que a perspectiva linguística está longe de ser a visão comum nos discursos que circulam sobre os usos linguísticos.

Os estudos sobre avaliações e percepções mostram quão automáticas e sistemáticas são as associações feitas pelos ouvintes entre determinados usos linguísticos e certos significados sociais. Assim como a produção linguística, as percepções são igualmente variáveis e exibem heterogeneidade ordenada (OUSHIRO, 2015): nem todos os ouvintes reagem a um estímulo linguístico do mesmo modo, mas suas respostas se distribuem de modo ordenado e previsível. Tomem-se como exemplo os resultados sobre as percepções acerca das variantes tepe e retroflexa de /-r/ em São Paulo (como em "quartel"), no estudo de Oushiro $(2015,2019)$. A Figura 1 mostra a diferença entre médias de julgamento para o grau de "paulistanidade" atribuído a um estímulo auditivo quando se ouviu tepe (T) ou retroflexo (R); para todos os grupos, a diferença da média de $\mathrm{R}-\mathrm{T}$ foi negativa, de modo que o retroflexo foi considerado menos paulistano do que o tepe. No entanto, a atribuição do grau de paulistanidade também depende da região de residência e da origem do ouvinte: os residentes de regiões centrais atribuíram maior grau de diferença entre a "paulistanidade" do tepe e do retroflexo do que residentes de regiões periféricas da cidade; e os ouvintes advindos do interior do estado de São Paulo diferenciam o grau de paulistanidade das variantes mais do que os nativos da cidade e da Grande São Paulo, ao passo que, para ouvintes de outros estados, tepe e retroflexo não se diferenciam quanto à sua paulistanidade. 
Figura 1. Diferença entre médias de julgamento para a escala de Paulistanidade quando se ouviu a variante retroflexa (R) ou tepe $(T)$ de / $r$ / em coda, de acordo com Região de Residência (acima) e Origem do ouvinte (abaixo). $+p>0,05 ;{ }^{*}<<0,05 ; * \star p<0,01 ; * \star * p<0,001$

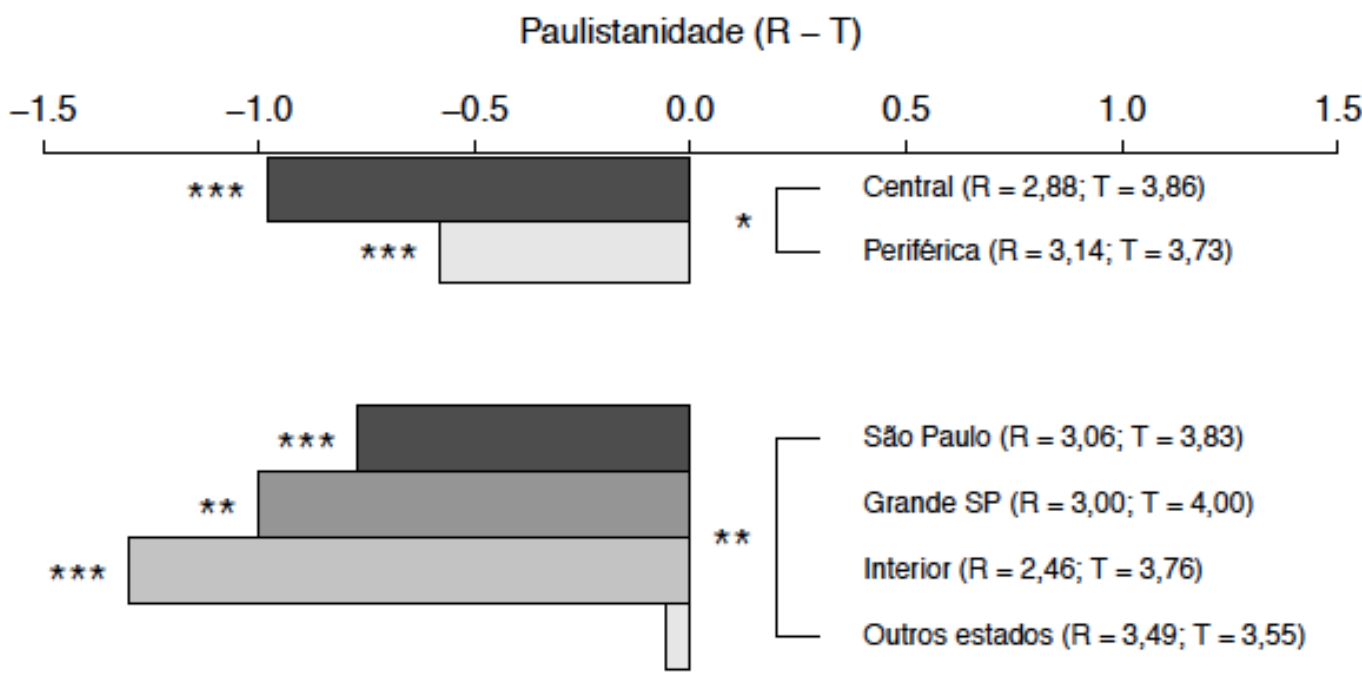

Fonte: Oushiro (2015, p. 296)

Esses dados deixam claro que as experiências linguísticas dos indivíduos têm influência sobre suas percepções: na região periférica de São Paulo, o retroflexo é mais frequente do que nas regiões centrais, de modo que os moradores de periferia parecem ser mais "tolerantes" quanto à paulistanidade do retroflexo (OUSHIRO, 2015). Quanto ao local de origem, é curioso notar que o grupo que mais diferencia tepe e retroflexo quanto à paulistanidade não são os paulistanos nativos, mas os falantes do interior, possivelmente porque são frequentemente reconhecidos como não nativos justamente por conta de sua realização do /r/ em coda. Ouvintes de outros estados (que, nessa amostra, referemse principalmente a nordestinos) não diferenciam tepe e retroflexo quanto ao grau de paulistanidade provavelmente porque, para esses ouvintes, ambas as variantes são "não nativas".

Para reconhecimento e atribuição de significado a esses traços, é necessário, efetivamente, fazer parte da comunidade linguística: um paulista pode categorizar com relativa facilidade se um falante é da capital ou do interior do estado, mas tal distinção pode não ser tão clara para pessoas de outros estados. Isso é uma evidência de que a capacidade de ouvir um falante e sobre ele fazer inferências faz parte de nossa competência comunicativa (HYMES, 1991 [1979]) - objeto por excelência dos estudos sociolinguísticos. De acordo com a definição de Hymes (1991 [1979]), a competência comunicativa compreende o conhecimento não só das formas gramaticais de uma língua, mas também de sua factibilidade, adequação e efetivo uso por parte dos membros de 
uma comunidade linguística. O conhecimento de todos esses aspectos está relacionado com os significados atribuídos às formas linguísticas.

Entretanto, se tais conhecimentos e tais significados atribuídos às variantes - que são, necessariamente, múltiplos, variáveis e ordenados - fazem parte da competência comunicativa dos falantes membros de uma comunidade de fala, e se tais associações entre significados sociais e variantes linguísticas são tão automáticas e sistemáticas, entende-se daí por que o discurso linguístico em favor da diversidade tende a cair em ouvidos moucos: a dificuldade de romper com um discurso que atribui características a variantes como "mais correto" e "mais bonito", "errado" ou "feio", implica em tentar suprimir significados que fazem parte do conhecimento linguístico dos falantes e são definidores das comunidades linguísticas; compartilhar certos valores significa fazer parte ou não de determinada comunidade de fala.

Com isso, não se pretende naturalizar o preconceito linguístico, de modo algum. É necessário reconhecer, no entanto, que preconceitos linguísticos não vão simplesmente desaparecer ao chamar a atenção para eles, pois uma série de inferências são feitas de modo automático ao ouvir um falante. Como exatamente funciona o mecanismo de associação entre determinados usos linguísticos e certos significados sociais é objeto do estudo de avaliações e percepções, área que ainda tem muito a expandir. A próxima seção trata de métodos e de conceitos centrais para seu estudo.

\section{Métodos e conceitos centrais para o estudo de avaliações e percepções}

Em seus estudos sobre percepções acerca da fala gay, Mendes (2012, 2018) propõe a seguinte questão: o que ouvimos na fala de uma pessoa que nos leva a categorizá-la como possivelmente gay? Essa mesma pergunta pode ser adaptada para abarcar outros significados sociais: o que ouvimos na fala de uma pessoa que nos leva a categorizá-la como possivelmente $X$, em que $X$ pode receber os mais diversos significados e "rótulos" sociais: paulista/nordestino/carioca? Patricinha/mauricinho? Pedante? Culto? De classe baixa? asiático? etc. Tal questão se lança na busca de traços linguísticos - fonéticos, fonológicos, prosódicos, morfológicos, sintáticos, lexicais etc. - que possivelmente se associam a certo grupo social. De forma alternativa ou complementar, pode-se também questionar: quais significados sociais estão associados às variantes da variável Y (a pronúncia de /r/ em coda, a concordância nominal, a morfologia de subjuntivo etc.)?

Uma das principais dificuldades no estudo de avaliações e percepções é o fato de que, nesse campo, lida-se com subjetividades, mas, como em qualquer pesquisa científica, o pesquisador deve analisar seu tópico do modo mais objetivo possível. O pesquisador deve evitar ao máximo cair em "achismos" e evitar impor suas próprias avaliações e percepções sobre os dados. Para tanto, é fundamental que se apliquem métodos bem 
definidos, que sejam replicáveis em outros estudos, que abarquem diversos participantes - uma vez que as avaliações e as percepções também são variáveis - e cujos resultados sejam, de algum modo, quantificáveis, a fim de evitar afırmações impressionísticas por parte do analista.

Outra dificuldade é determinar quais informações contextuais são recolhidas pelo ouvinte na formação de suas impressões sobre um falante, uma vez que em qualquer evento de fala coocorrem diversas variáveis: o conteúdo da mensagem, a qualidade da voz, ritmo da fala, fatores suprassegmentais e variáveis fonéticas, morfológicas, sintáticas, além de outros fatores situacionais e sociais.

Metodologicamente, estudos sobre avaliações e percepções têm se beneficiado do diálogo com áreas experimentais, como a Psicologia Social, a Psicolinguística, a Fonética Experimental e a Fonologia de Laboratório. Para acessar avaliações e percepções de indivíduos sobre diferentes formas linguísticas, pode-se empregar tanto métodos diretos quanto indiretos. Aqui, com efeito, os conceitos de avaliação e percepção diferenciam-se justamente quanto ao grau de consciência dos falantes sobre suas reações a estímulos linguísticos. O termo avaliação é entendido como o discurso metalinguístico explícito dos indivíduos sobre variantes, variedades e línguas - como dizer que a concordância não padrão é "feia" e "errada"--, enquanto as percepções dizem respeito às reações subjetivas e às inferências feitas pelos usuários de uma língua ao ouvir outro falante, o que pode ou não ser consciente 4 .

Tanto métodos diretos quanto indiretos trazem informações preciosas para o estudo das subjetividades. Um método direto é realizar perguntas explícitas voltadas a certas formas linguísticas, pedindo ao participante que comente o que pensa sobre elas. Por exemplo, no Projeto SP2010 (MENDES; OUSHIRO, 2012), o roteiro de perguntas, que foi aplicado a 60 participantes paulistanos, incluía questões que pediam ao informante que comentasse sobre os seguintes modos de falar: (i) "meu, você tá entendendo o que eu tô dizendo?", em que /e/ nasal deveria ser pronunciado com a variante exageradamente ditongada [ẽj]; (ii) "a porta tá aberta", que o documentador deveria pronunciar com retroflexos e, posteriormente, com tepes/vibrante múltipla; e (iii) e "meu, me vê dois pastel e um chopes", com ausência da marca de número no sintagma "dois pastel". Para cada uma dessas sentenças, o documentador pedia, inicialmente, por uma opinião ("o que você acha desse modo de falar?"); se o informante manifestasse uma atitude negativa, o documentador perguntava o que estava "errado", "estranho" ou "esquisito", e como o falante acha que deveria ser a forma mais "correta" ou "natural" - seguindo os termos usados pelo participante; se se trata de um fenômeno generalizado ou se é mais

4 Entende-se, contudo, que a "questão da avaliação", como postulada por Weinreich, Labov e Herzog (2006 [1968]), é um tópico "guarda-chuva" que abarca avaliações e percepções de modo amplo. 
característico de um grupo específico de pessoas na cidade; e, por fim, o documentador pergunta se o falante também emprega essas formas (OUSHIRO, 2016).

Sendo as avaliações variáveis e ordenadas, cabe ao pesquisador levantar toda e qualquer resposta dada, esforçando-se para entender as regularidades e padrões. Vale contrastar aqui os metacomentários feitos pelos paulistanos para os estímulos com as variantes retroflexa e tepe de /r/ em coda na frase "a porta tá aberta", resumidos nas nuvens de palavras das Figuras 2 e 3 respectivamente.

Figura 2. Nuvem de palavras associada à sentença "a porta tá aberta", realizada com /r/ em coda retroflexo

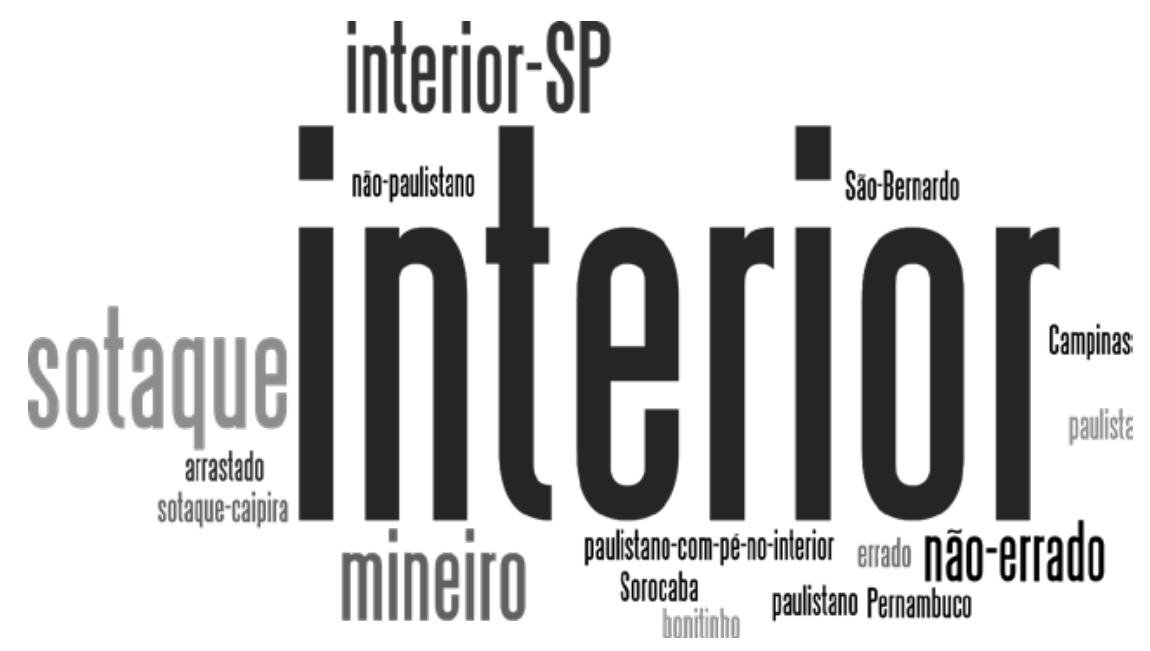

Fonte: Oushiro $(2015$, p. 98)

Figura 3. Nuvem de palavras associada à sentença "a porta tá aberta", realizada com /r/ em coda tepe
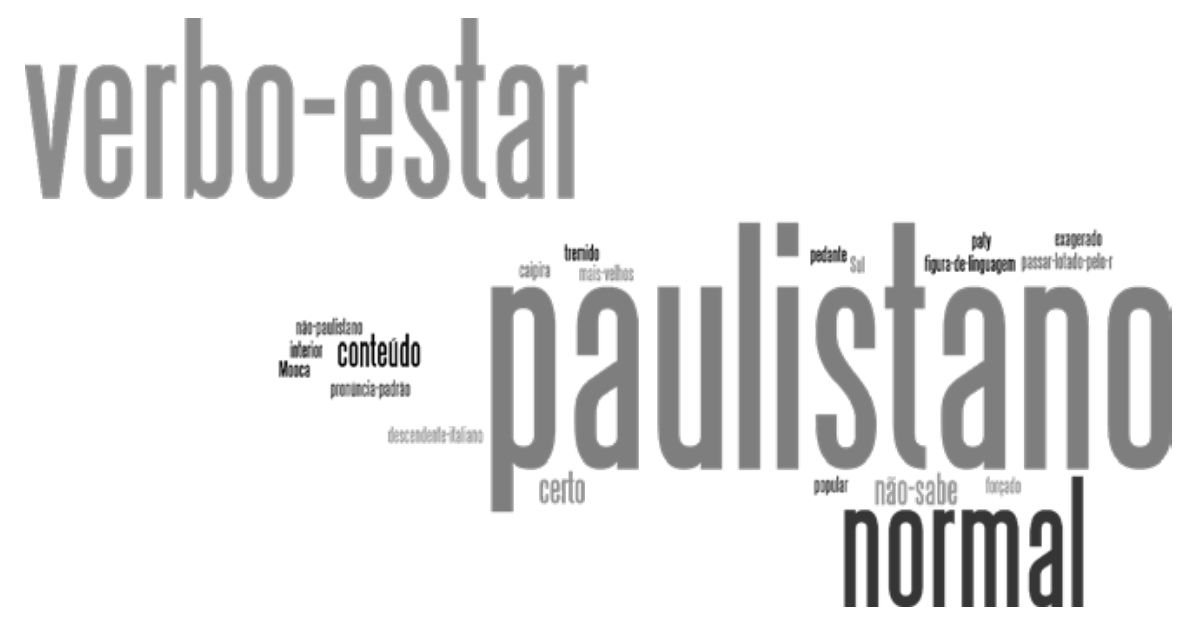

Fonte: Oushiro (2015, p. 101) 
As nuvens de palavras representam a frequência de menção de palavras-chave por meio do tamanho da fonte. Na Figura 2, nota-se claramente que a principal associação da sentença "a porta tá aberta" realizada com / $\mathrm{r}$ / em coda retroflexo é com o "interior", ora definido como o "interior do estado de São Paulo", "mineiros", ou por meio de locais específicos ("Campinas", "Sorocaba"), ora também definido como um "sotaque". Em contraste, a mesma sentença realizada com / $r$ / tepe (Figura 3) tende a ser classificada como o modo "paulistano" de falar, mas, curiosamente, o termo "sotaque" não aparece com a mesma frequência; muitos afirmam que se trata do modo "normal" de se dizer a frase e outros, ainda, não comentam o modo de realização do segmento /r/, mas sim a redução do verbo "estar" para "tá", sinalizando que não há o que se comentar sobre a realização de /r/ em coda nesse caso. A ausência de comentários explícitos por parte de muitos participantes é tão informativa quanto aquilo que mencionam de fato.

Métodos diretos como perguntas específicas podem revelar o grau de consciência dos falantes sobre as formas linguísticas, o que deve ter consequências para a mudança linguística e a manipulação (consciente ou não) desses traços na projeção de personae. A classificação de variáveis como marcadores, indicadores e estereótipos (LABOV, 2008 [1972]) é distinção essencial para os estudos sobre avaliações e percepções.

As respostas dos participantes para perguntas diretas não precisam ser apenas verbais. Ciller e Florez (2016), por exemplo, buscaram avaliações de 25 falantes bilíngues de Tucson (Arizona, EUA) sobre sua própria variedade de espanhol e de outras localidades. Para as perguntas "Onde se fala o melhor espanhol?" e "Onde se fala o pior espanhol?", os participantes deveriam clicar sobre imagens com mapas do continente americano e europeu; os locais mais frequentemente selecionados são representados por meio de mapas de calor, como na Figura 4.

Figura 4. Mapa de calor com respostas para a pergunta "Onde se fala o melhor espanhol?" a falantes bilíngues espanhol-inglês de Tucson-AZ, EUA

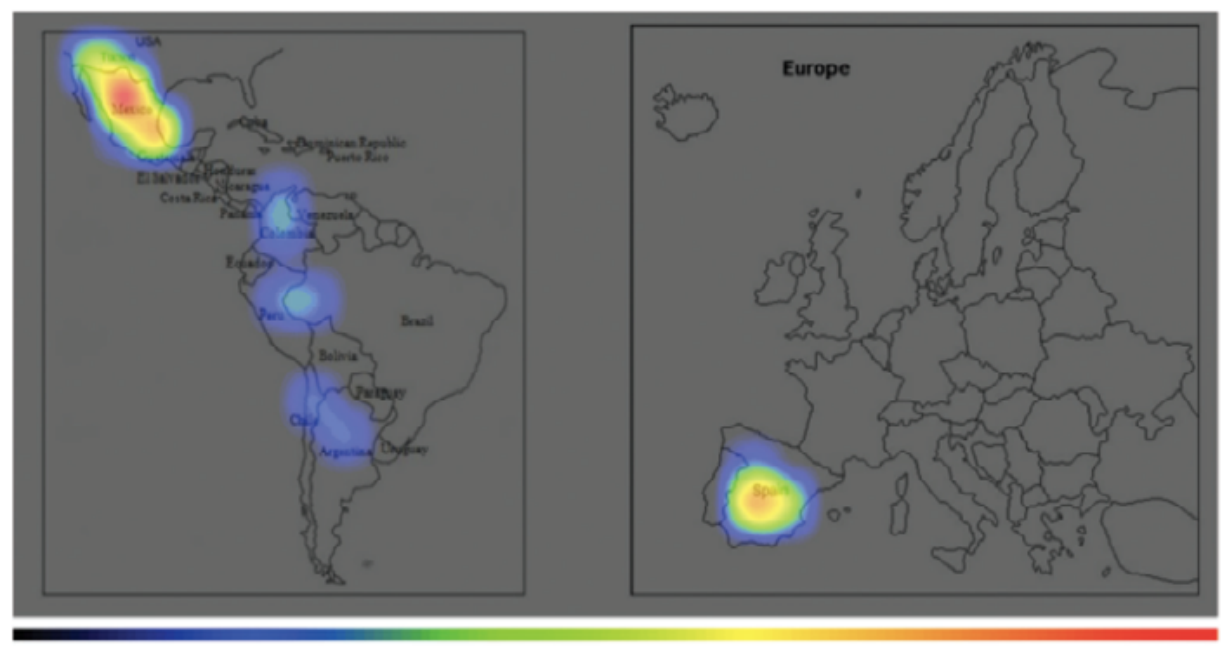

Fonte: Ciller e Florez (2016, p. 107) 
O uso de mapas é comum nos trabalhos de dialetologia perceptual (ver, p.ex., PRESTON, 1999) para a representação da variação nas avaliações sobre diferentes dialetos. A Figura 5, retirada de Preston (2013), mostra a nota média dada por respondentes do estado de Michigan para quão "correta" consideram a variedade falada em diferentes estados. Nota-se aí a tendência à atribuição de maior nota para a própria variedade e a de falares próximos, na região do Meio-Oeste, próxima à fronteira com o Canadá, e a atribuição de menores notas aos estados do Sul. Na aplicação da metodologia da dialetologia perceptual, evidentemente, é possível eliciar diversos tipos de avaliações, não só quanto à "correção" dos falares, mas sua agradabilidade, dinamicidade, beleza e outras tantas dimensões.

Figura 5. Média das notas de "correção" linguística para o inglês norte-americano por respondentes de Michigan (em uma escala de 1-10, em que 1 = menos e 10 = mais correto)

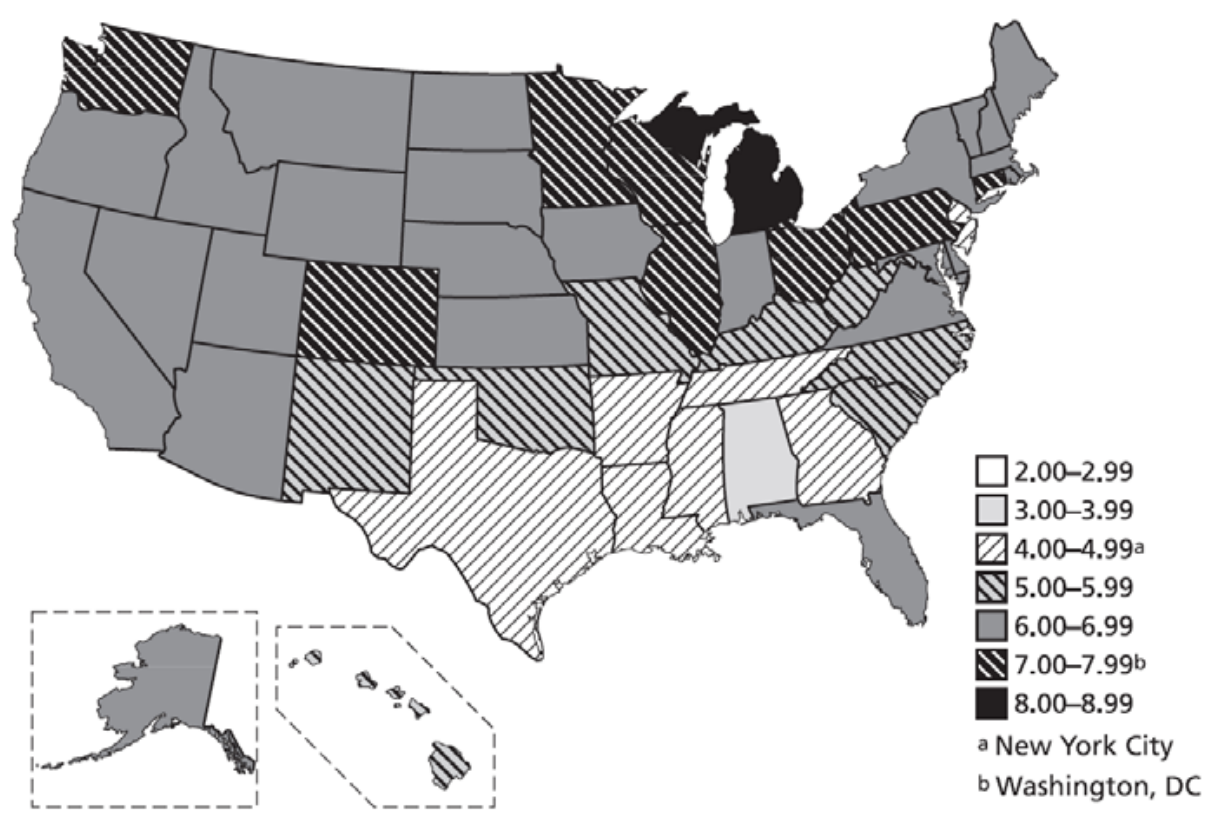

Fonte: Preston (2013, p. 174)

Por outro lado, métodos indiretos podem capturar reações subjetivas e inconscientes dos participantes quanto a diferentes línguas, variedades ou variantes linguísticas. A técnica de estímulos pareados (matched-guise), desenvolvida por Lambert et al. (1960), é um dos métodos indiretos mais utilizados em pesquisas sobre percepções (sobre o português, ver, p. ex., OUSHIRO, 2015; SORIANO, 2016; CANEVER, 2017; MENDES, 2018; SANTOS, 2020; BARCELLOS, 2020). A técnica consiste no controle das variáveis que podem ter influência sobre as percepções dos falantes, criando-se pares de estímulos idênticos em todos os aspectos exceto pelo traço sob enfoque. No experimento original, quatro bilíngues canadenses leram um mesmo texto de natureza filosófica em inglês e em francês, de modo a controlar o efeito do conteúdo das mensagens sobre as percepções dos ouvintes. As oito gravações, às quais foram acrescidos dois estímulos distratores de 
outros falantes, foram apresentadas a diversos ouvintes-juízes francófonos e anglófonos que, acreditando estar diante de 10 vozes diferentes, julgaram os falantes quanto a 14 características pessoais, como altura, boa aparência física, ambição, caráter, simpatia. A "lógica" por trás da técnica é que se um mesmo falante for avaliado diferentemente a depender de se ouvido no disfarce em inglês ou em francês, tais diferenças podem ser atribuídas a atitudes quanto à língua empregada, não ao falante em si. Mais recentemente, em vez do uso de leituras, tem-se dado preferência para trechos de fala natural, manipulados com softwares de áudio como o Praat, como no estudo de Oushiro $(2015,2019)$.

A técnica verbal-guise, de modo semelhante, elicia reações dos participantes por meio de estímulos linguísticos; diferentemente do matched-guise, contudo, os estímulos não são controlados a ponto de haver pares que diferem em apenas um aspecto (como a língua, a variedade ou uma variante). Por exemplo, no estudo de Lopes et al. (2016) a respeito de percepções sobre os pronomes de $2^{a}$ pessoa do singular tu e você por parte de cariocas, os participantes eram convidados a avaliar legendas para diferentes cenas de filmes e seriados; os pesquisadores analisaram as sentenças-alvo, nas quais aparecia um dos pronomes de $2^{a}$ pessoa, quanto ao grau de adequação atribuído pelos participantes comparando-se o tipo de relação entre os interlocutores (simétrica ou assimétrica) nas cenas. Embora os autores tenham buscado cenas comparáveis - como duas cenas de um casal de namorados jovens conversando, uma à qual se atribuiu tu e a outra você -, cada cena foi apresentada com apenas um dos pronomes, configurando-se, assim, um estudo do tipo verbal-guise.

Outra técnica que elicia reações inconscientes dos participantes é o Teste de Associação Implícita (Implicit Association Test - IAT), ainda pouco utilizado em estudos brasileiros. A técnica busca revelar associações implícitas e inconscientes entre certas categorias, como flor-bom e inseto-ruim. No estudo de Biasibetti (2020), a autora investiga a associação implícita entre as categorias "nativo" vs. "não-nativo" e a realização de /s/ em coda como alveolar [s] ou como fricativa pós-alveolar [J] em Florianópolis, sob a hipótese de que há uma associação implícita entre a fricativa pós-alveolar e a categoria "florianopolitano". Nesse tipo de teste, os participantes devem classificar uma série de estímulos (que podem ser visuais, escritos ou auditivos) que aparecem no centro da tela do computador em categorias nos cantos à esquerda ou à direita, escolhendo-as por meio de teclas específicas no computador (p. ex., "E" à esquerda e "I" à direita). A autora apresentou aos participantes seis estímulos auditivos - as palavras "pasta", "pista" e "custo" realizadas com /s/ alveolar ou pós-alveolar - e seis estímulos visuais - imagens associadas a Florianópolis (Ponte Hercílio Luz, praia e frutos do mar) ou não (chá mate, araucária e Avenida Paulista, associados ao Rio Grande do Sul, Paraná e São Paulo). Em certos blocos, os participantes visualizam, no mesmo lado da tela, categorias que se hipotetizam relacionadas, a condição chamada "congruente" (p.ex., [f] e "nativo" do lado esquerdo, e [s] e "não-nativo" do lado direito), e em outros blocos, os participantes visualizam as categorias de modo invertido, a condição chamada "não congruente" 
(p. ex., [ [] e "não-nativo" no mesmo lado da tela). Quando há uma associação implícita entre duas categorias, obtêm-se respostas mais rápidas aos estímulos quando se encontram na condição "congruente".

As metodologias mencionadas acima - que de modo algum esgotam as técnicas e as possibilidades analíticas de avaliações e percepções - permitem descrever correlações e associações entre determinados significados, por um lado, e certos usos linguísticos, por outro. O modo pelo qual se efetuam tais associações, no entanto, ainda não é tão claro, mas um construto promissor é o conceito de campos indexicais de Eckert (2008). A autora afirma:

[...] os significados das variáveis não são precisos ou fixos, mas constituem um campo de significados potenciais - um campo indexical, ou constelação de significados ideologicamente relacionados, qualquer um dos quais pode ser ativado no uso situado da variável. O campo é fluido, e cada nova ativação tem o potencial de mudá-lo ao ampliar as ligações ideológicas. Assim, a variação constitui um sistema indexical que incorpora a ideologia na linguagem e que é, por sua vez, parte essencial da construção da ideologia. (ECKERT, 2008, p. 454, grifo da autora) $)^{5}$.

O conceito de campo indexical parte de uma crítica aos estudos variacionistas que, desde o trabalho inicial de Labov (2008 [1963]) em Martha's Vineyard, têm abandonado o interesse sobre o significado social da variação em favor de amplos processos linguísticos, como a Mudança Vocálica das Cidades do Norte no inglês norte-americano; nesse percurso, segundo Eckert $(2008,2012)$, o significado social passou a se confundir com as correlações demográficas que identificam as categorias de falantes que tendem a empregar determinadas variantes.

Eckert (2008) se baseia no conceito de Silverstein (2013) de "ordem indexical" para compor um modelo de significados sociolinguísticos. Em diálogo com os conceitos labovianos de indicadores, marcadores e estereótipos, Silverstein define os índices de primeira ordem de modo semelhante a indicadores, variantes geográficas ou diastráticas que não se diferenciam em graus de formalidade. A avaliação social sobre os falantes que as empregam pode vir a se associar ao índice e se internalizar nos dialetos dos falantes para indexar outros elementos específicos; segundo Silverstein, nesse ponto, o traço se torna

5 No original: "[...] the meanings of variables are not precise or fixed but rather constitute a field of potential meanings - an indexical field, or constellation of ideologically related meanings, any one of which can be activated in the situated use of the variable. The field is fluid, and each new activation has the potential to change the field by building on ideological connections. Thus variation constitutes an indexical system that embeds ideology in language and that is in turn part and parcel of the construction of ideology.". 
um marcador ou índice de segunda ordem. A diferença entre o conceito laboviano e o de Silverstein é que, para o último, um índice sempre está disponível para reinterpretação ou atribuição de novos significados, processo que se dá no discurso e em contexto, em um constante reexame das formas linguísticas. Eckert chama a atenção para o fato de que, embora os termos "primeira, segunda, enésima ordem" possam implicar uma linearidade, a possibilidade de superposição de novos significados caracteriza o campo ideológico de associações de modo fluido e dinâmico.

No plano teórico, o modelo de ordens e campos indexicais abre caminho para uma representação mais complexa e coerente com o que se observa nos usos e nas percepções linguísticas. Eles permitem explicar, por exemplo, por que nem todos os falantes e grupos sociais reagem às mesmas variantes homogeneamente; por que um mesmo termo pode se associar a duas variantes da mesma variável; ou por que a correlação de uma variável com grau de escolarização do falante se estende para a atribuição de inteligência em alguns casos e não em outros.

Por outro lado, uma limitação do modelo de Eckert (2008) é o fato de não explicitar como se formam campos indexicais, para além de exemplos genéricos e especulativos. A fim de sanar essa questão, Oushiro (2019) propõe a modelagem de campos indexicais por meio de um método computacional, a Árvore de Distâncias Mínimas, com vistas a representar múltiplas correlações simultâneas entre diversas variáveis. Conforme se argumentou mais acima, o levantamento sistemático de respostas e a possibilidade de quantificação e modelagem dos dados é fundamental no estudo de avaliações e de percepções, a fim de evitar afırmações impressionísticas, com base apenas nas atitudes do próprio pesquisador.

Qualquer que seja o método escolhido para a pesquisa, é importante, antes de mais nada, bem definir quais são as perguntas de pesquisa - que podem, aliás, ajudar a definir o método mais adequado a ser empregado. Em diversos tipos de experimentos, é necessário estabelecer uma fase de treino ao participante, cuidar para que as tarefas não sejam longas e demasiado cansativas (em geral, recomenda-se não ultrapassar 15 minutos), incluir estímulos distratores para que os participantes não percebam de que se trata o estudo, randomizar os estímulos (para uma revisão detalhada de métodos experimentais, ver DRAGER, 2018). Tudo isso faz com que em estudos sobre avaliações e percepções seja comum que a fase de montagem e planeamento da coleta de dados ocupe mais tempo do que a coleta em si.

$\mathrm{Na}$ análise dos dados, sempre que possível, é recomendável quantificar as respostas, como modo de manter a objetividade sobre o que é generalizável ou não. Certas avaliações ou percepções que correspondem àquelas do pesquisador podem não ser, na verdade, as mais recorrentes e as mais representativas da amostra. 


\section{Considerações finais}

Este artigo apresentou algumas das motivações para o desenvolvimento de estudos sobre avaliações e percepções sociolinguísticas, bem como alguns dos métodos e cuidados para as pesquisas do campo. Todos os falantes - inclusive os linguistas - têm suas próprias avaliações e percepções acerca de diferentes usos linguísticos, mas o estudo sistemático dessas subjetividades deve se pautar por métodos objetivos e replicáveis, a fım de se afastar de afirmações impressionísticas.

Embora existam trabalhos descritivos que correlacionam certos significados, grupos sociais e variantes linguísticas, a questão da avaliação tem sido relativamente menos explorada em comparação com estudos de produção, de modo que pouco ainda se sabe sobre os mecanismos que levam à associação de certos usos com certos significados. Aqui se argumentou, entretanto, que tais associações são, na maior parte das vezes, automáticas por parte dos ouvintes, pois fazem parte da competência comunicativa dos membros de uma comunidade de fala; assim, o discurso de combate ao preconceito linguístico deve se informar dos resultados de pesquisas sobre avaliações e percepções, que por sua vez ainda precisam se expandir, a fim de mais bem compreendermos como os ouvintes fazem inferências sobre os falantes e como certos usos adquirem novos significados no uso situado da variação linguística.

\section{Agradecimentos}

Agradeço aos participantes do minicurso "Avaliações e percepções sociolinguísticas" na I Escola de Estudos Linguísticos do GEL, ocorrido no segundo semestre de 2020, pelas reflexões e pelos materiais compartilhados, que contribuíram para o amadurecimento dessas notas. Quaisquer erros ou limitações, éclaro, são de minha inteira responsabilidade.

\section{REFERÊNCIAS}

BARCELLOS, M. E. M. O falar paulistano e os significados sociais de (AN): correlações entre origem do ouvinte e percepção. 2020. Dissertação (Mestrado em Linguística) - Faculdade de Filosofia, Letras e Ciências Humanas, Universidade de São Paulo, São Paulo, 2020.

BIASIBETTI, A. P. C. da S. Cognitive biases on the social perception of the allophonic variation of coda /S/ in Brazilian Portuguese. Journal of Portuguese Linguistics, v. 19, n. 1, out. 2020 [não paginado].

CANEVER, F. Infinitivo flexionado em português brasileiro: frequência e percepções sociolinguísticas. 2017. Tese (Doutorado em Linguística) - Faculdade de Filosofia, Letras e Ciências Humanas, Universidade de São Paulo, São Paulo, 2017. 
CILLER, J. F. C.; FLOREZ, C. F. On attitudes towards Spanish varieties: a bilingual perspective. Todas as Letras, v. 18, n. 2, p. 98-116, 2016.

DRAGER, K. Experimental Research Methods in Sociolinguistics. London: Bloomsbury, 2018.

ECKERT, P. Variation and the indexical field. Journal of Sociolinguistics, v. 12, n. 4, p. 453476, 2008.

ECKERT, P. Three waves of variation study: the emergence of meaning in the study of variation. Annual Review of Anthropology, v. 41, p. 87-100, 2012.

FReITAG, R. M. K.; SEVERO, C. G.; SNICHELOTtO, C. A. R.; TAVARES, M. A. Como os brasileiros acham que falam? Percepções sociolinguísticas de universitários do Sul e do Nordeste. Todas as Letras, v. 18, n. 2, p. 64-84, 2016.

GUY, G. R. Language variation and linguistic theory, Ms., s/d.

HYMES, D. On communicative competence. In: BRUMFIT, C. J.; JOHNSON, K. (ed.). The Communicative Approach to Language Teaching. Oxford: Oxford University Press, 1991 [1979]. p. 5-26.

LABOV, W. Padrões sociolinguísticos. Tradução Marcos Bagno, Maria Marta Pereira Scherre e Caroline R. Cardoso. São Paulo: Editora Parábola, 2008 [1972].

LABOV, W. The social stratification of English in New York City. São Paulo: Cambridge University Press, 2006 [1966].

LAMBERT, W. E. et al. Evaluational reactions to spoken languages. Journal of Abnormal and Social Psychology, v. 60, n. 1, p. 44-51, 1960.

LOPES, C. R. dos S.; OLIVEIRA, T. L. de; CARVALHO, B. B. A. de. A expressão da $2^{a}$ pessoa do singular: variação e percepção numa abordagem experimental. Todas as Letras, v. 18, n. 2, p. 117-132, 2016.

MENDES, R. B. Percepção e performance de masculinidades. 2018. Tese (Livre Docência) - Faculdade de Filosofia, Letras e Ciências Humanas, Universidade de São Paulo, São Paulo, 2018.

MENDES, R. B. Diphthongized (en) and the indexation of femininity and Paulistanity. Cadernos de Estudos Linguísticos, v. 58, n. 3, p. 425-444, 2016. 
MENDES, R. B. Diminutivos como marcadores de sexo/gênero. Revista Linguística, v. 8, n. 1, p. 113-124, 2012.

MENDES, R. B.; OUSHIRO, L. O paulistano no mapa sociolinguístico brasileiro. Alfa, v. 56, n. 3, p. 973-1001, 2012.

MENDES, R. B.; OUSHIRO, L. Variable number agreement in Brazilian Portuguese: an overview. Language and Linguistics Compass, v. 9, n. 9, p. 358-368, $2015 a$.

MENDES, R. B.; OUSHIRO, L. Diverging social perceptions: coda (-r) and variable number agreement in São Paulo Portuguese. In: NEW WAYS OF ANALYZING VARIATION 44, 2015b.

OUSHIRO, L. A computational approach for modeling the indexical field. Revista de Estudos da Linguagem, v. 27, n. 4, p. 1737-1786, 2019.

OUSHIRO, L. O que se diz e como se fala: relações entre o discurso metalinguístico e a variação linguística. Signo y Seña, v. 28, p. 139-167, 2016.

OUSHIRO, L. Identidade na pluralidade: avaliação, produção e percepção linguística na cidade de São Paulo. 2015. Tese (Doutorado em Semiótica e Linguística Geral) - Faculdade de Filosofia, Letras e Ciências Humanas, Universidade de São Paulo, São Paulo, 2015.

PRESTON, D. Language with an attitude. In: CHAMBERS, J. K.; SCHILLING, N. (ed.). The Handbook of Language Variation and Change. 2. ed. Malden/MA: Wiley-Blackwell, 2013. p. 157-182.

PRESTON, D. Handbook of Perceptual Dialectology. v. 1. Amsterdam \& Philadelphia: John Benjamins, 1999.

PURNELL, T.; IDSARDI, W.; BAUGH, J. Perceptual and phonetic experiments on American English dialect identification. Journal of Language and Social Psychology, v. 18, n. 1, p. 1030, 1999.

RUBIO, C. F.; GONÇALVES, S. C. L. A fala do interior paulista no cenário da sociolinguística brasileira: panorama da concordância verbal e da alternância pronominal. Alfa, v. 56, n. 3, p. 1003-1034, 2012. 
SANTOS, W. S. dos. Percepções sociolinguísticas acerca da variação subjuntivo/indicativo em São Luís e São Paulo. 2020. Tese (Doutorado em Semiótica e Linguística Geral) Faculdade de Filosofia, Letras e Ciências Humanas, Universidade de São Paulo, São Paulo, 2020.

SILVERSTEIN, M. Indexical order and the dialectics of sociolinguistic life. Language and Communication, v. 23, p. 193-229, 2003.

SORIANO, L. G. M. Percepções sociofonéticas do (-r) em São Paulo. 2016. Dissertação (Mestrado em Semiótica e Linguística Geral) - Faculdade de Filosofia, Letras e Ciências Humanas, Universidade de São Paulo, São Paulo, 2016.

WEINREICH, U.; LABOV, W.; HERZOG, M. I. Fundamentos empíricos para uma teoria da mudança linguística. Tradução Marcos Bagno. São Paulo: Parábola, 2006 [1968]. 